\title{
APPARENT DECLINE OF MIGRANT COMMON NIGHTHAWKS NEAR PINAWA, MANITOBA
}

\author{
PETER TAYLOR, Box 597, Pinawa, MB. ROE 1 Lo
}

Concern about declining numbers of Common Nighthawks led to inclusion of this species on the American Birds Blue List in 1976. ${ }^{1}$ The Common Nighthawk breeds in both urban and wilderness settings. Breeding populations in forested regions are difficult to monitor. Activity falls off rapidly at daybreak, so that nighthawks are underrepresented on Breeding Bird Survey (BBS) runs. For example, I have recorded grand totals of only eight Common Nighthawks on 18 runs of the Bird River BBS route in southeastern Manitoba 1978-95, and 12 on seven runs of the neighbouring Springer Lake BBS route 1989-95. Urban nighthawk populations are somewhat more amenable to monitoring. Wedgwood recently reported an apparent threefold decline in breeding density of Common Nighthawks in Saskatoon, from one male per $1.4 \mathrm{~km}^{2}$ in 1971 to one per $3.8 \mathrm{~km}^{2}$ in $1990 .^{9}$

Ewins and Carley described concentrations of hundreds of foraging Common Nighthawks during fall migration, 23-24 August 1992 in Toronto. ${ }^{3,5}$ Comparable observations in southeastern Manitoba date back at least to 1928, although published details are sparse. ${ }^{7}$ Flocks of Manitoba birds may contribute to the immense concentrations (over 10,000 birds) that have been reported in August at Duluth, Minnesota. ${ }^{2,6}$

Shortly after moving to Pinawa in 1975 I noted that, during August, nighthawk flocks occurred regularly near the Pinawa sewage lagoons and, to a lesser extent, over the town itself. Peak counts of over 100 birds were noted annually between 1976 and 1981. My record keeping was more sporadic between 1982 and 1991 but I gained the impression that numbers were lower than in previous years. This prompted a more systematic evening survey of nighthawk flocks near the sewage lagoons between 1992 and 1995. This survey provided more convincing evidence of a decline in numbers. The results are presented here along with information that might be helpful in developing survey methods elsewhere.

Study Area and Methods The Pinawa sewage lagoons are located about $1 \mathrm{~km}$ west of the town in a large clearing of the forest alongside the Winnipeg River. This situation permits unobstructed scanning of the sky down to low elevations, and actively foraging nighthawks can be detected with binoculars up to about 1 $\mathrm{km}$ away in all directions. Counting erratically flying nighthawks is a challenge but accurate counts (repeatable within $5-10 \%$ ) are possible through $360^{\circ}$ binocular scans of loose flocks of up to about 100 birds. Estimation becomes much more difficult for larger or tightly concentrated flocks.

As a rule, nighthawk numbers build up rapidly around sunset and peak shortly before fading light starts to hamper observation. For example, on 22 August 1994 one nighthawk appeared at 8:21 p.m., numbers increased to 30 by $8: 37$, and remained in the low 20 s until light started to fail at 8:50. The birds appear to disperse 


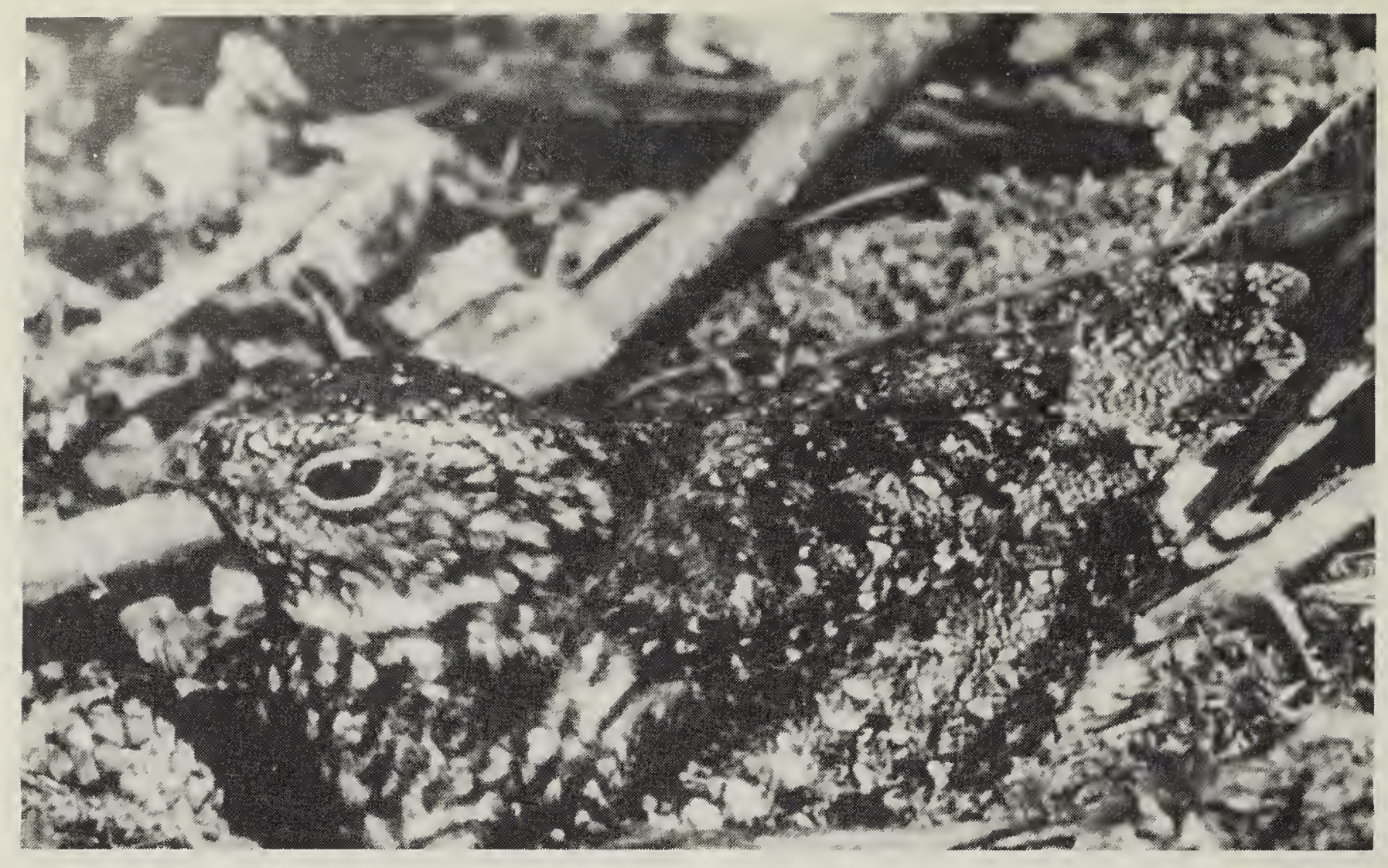

\section{Common Nighthawk}

again as darkness falls; they rarely vocalize. The exact locations where they concentrate vary from evening to evening, presumably as insect concentrations respond to weather changes. Sometimes the nighthawks mingle with, or replace, flocks of diurnal insectcatchers, such as swallows, Black Terns, and Bonaparte's Gulls. ${ }^{8}$

Occasionally, numbers of nighthawks appear much earlier in the evening and build up more slowly until dusk, much as described by Ewins. ${ }^{5}$ For example, on 23 August 1977 , numbers increased from 13 at 6:30 p.m. to 54 at $7: 40$ p.m. and 125 at $8: 30$ p.m. I suspect that this different pattern is associated with active migration as opposed to foraging by birds that have roosted locally and may be regarded as staging in the area. This is roughly consistent with the reported timing of heavy migrations at Duluth, Minnesota, as well as the Toronto observations cited above. ${ }^{2,3,5,6}$ Ken De Graaf reported a concentration of hundreds of Common Nighthawks about $30 \mathrm{~km}$ north of The Pas, Manitoba at 3 p.m. on 8 August 1977. ${ }^{4}$
Results In the following discussion all counts are totals of individuals visible at one time. It is difficult to estimate numbers of birds entering and leaving a concentration. On most evenings birds drifted in from the north either singly or in small groups, and formed loose foraging flocks. Only occasionally were birds obviously migrating; they typically headed east or southeast, often following the Winnipeg River.

Prior to 1992, Common Nighthawk counts at the Pinawa lagoons were noted during general bird observations which often finished before dusk. Between 1992 and 1995 I conducted deliberate nighthawk surveys and recorded maximum counts just before dark when activity usually peaked. Thus, if nighthawk numbers remained stable between 1977 and 1994, higher counts overall might be expected in the deliberate surveys than in the more casual observations. In fact, the reverse was true.

Concentrations of 10 or more Common Nighthawks have been observed at the Pinawa sewage 
Table 1: COMMON NIGHTHAWKS AT PINAWA, MANITOBA

SEWAGE LAGOONS FROM 11-25 AUGUST

\begin{tabular}{|r|r|r|}
\hline Number Observed & $1976-1981$ & $1992-1995$ \\
\hline $0-5$ & 5 & 7 \\
\hline $6-10$ & 0 & 5 \\
\hline $11-20$ & 0 & 12 \\
\hline $21-50$ & 3 & 8 \\
\hline $51-100$ & 5 & 2 \\
\hline $101+$ & 8 & 0 \\
\hline \hline & 21 & 34 \\
\hline
\end{tabular}

lagoons on dates between 12 July and 4 September and 100 or more from 3 August to 4 September. The highest counts were usually recorded from 11-25 August. In Tables 1 and 2 counts are summarized for 21 dates from 1976-81 and 34 dates from 1992-95, all from 11-25 August. The 1992 and 1993 surveys were scattered more or less uniformly through the 15-day reporting period, the 1994 surveys were run on 10 consecutive evenings (15-24 August) and the 1995 surveys were run almost daily through August.

Eight counts from 11-25 August and 12 counts in total exceeded 100 birds between 1976 and 1981. The highest were estimates of 300 birds on each of 14 August 1979 and 18 August 1980. In contrast, the largest concentration observed between 1992 and 1995 was 68 birds on 23 August 1993 and only three counts reached or exceeded 50 birds.

These results indicate roughly a three- to five-fold decline in fall migrant Common Nighthawk numbers in the Pinawa area between the late 1970 s and the early 1990s. More detailed analysis is not possible because the earlier surveys were not systematic. Surveys such as this from one location may only reflect subtle changes in local conditions rather than regional trends. This is especially true for migration counts, as compared with breeding bird surveys. Nevertheless, it is disturbing that these findings closely resemble those of the urban breeding survey in Saskatoon. ${ }^{9}$ They support a general impression of widespread decline in Common Nighthawk numbers.

Swallow counts at the Pinawa sewage lagoons do not show a similar decline to nighthawk numbers. Concentrations of 20 to 100 birds (mainly Barn and Cliff Swallows) were frequently observed, with occasional peaks of 200 to 250 birds, during both periods of observation (1976-81 and 1992-95). These were usually high-flying, foraging flocks in the same general area as the nighthawks. Therefore, it is unlikely that the reduction in nighthawk numbers is related to availability of flying insects.

If both urban and (presumed) boreal nesting populations of nighthawks are declining, the cause may lie in the wintering range. Both Common Nighthawks and Whip-poor-wills are frequently killed on secondary roads in the boreal forest of southeastern Manitoba. Analysis of roadkilled specimens for pesticide residues could help to evaluate one possible cause of decline.

Although there is evidence of a marked reduction in migrant nighthawk numbers in southeastern Manitoba since the late 1970 s, some recent sightings of active migration are impressive. Around 6:00 p.m. on 23 August 1993 Rudolf Koes observed 
Table 2: COMMON NIGHTHAWK COUNTS AND MAXIMA AT PINAWA, MANITOBA SEWAGE LAGOONS FROM 11-25 AUGUST

\begin{tabular}{|c|c|c|}
\hline Year & Number of Counts & Maximum (Day) \\
\hline 1976 & 5 & 145 (12th) \\
\hline 1977 & 6 & 130 (24th) \\
\hline 1978 & 4 & $30(16 \mathrm{th})^{\star}$ \\
\hline 1979 & 3 & 300 (14th) \\
\hline 1980 & 3 & 300 (18th) \\
\hline 1981 & 1 & 100 (18th) \\
\hline 1992 & 6 & 52 (15th) \\
\hline 1993 & 5 & 68 (23rd) \\
\hline 1994 & 10 & 30 (22nd) \\
\hline 1995 & 12 & 34 (20th) \\
\hline
\end{tabular}

over 400 Common Nighthawks, many of them heading east-southeast, between Beausejour and $\mathrm{Pi}$ nawa, Manitoba (a distance of $60 \mathrm{~km}$ ). Later that evening, a steady, dispersed flight was noted over Pinawa while earlier in the day, Paula Grieef and Victor Fazio estimated 1,300 nighthawks passing Delta, Manitoba heading southeast. A heavy movement was also noted in the southern Interlake region of Manitoba on 18 August 1995 when Ken Gardner saw at least 625 nighthawks at Stonewall and Jerry Weshnoweski saw at least 600 at Gimli.

The spring migration record is too erratic to provide any comparable information. Spring counts of Common Nighthawks in the Pinawa area rarely exceed 10 birds. An exceptional concentration of up to 160 birds at the Pinawa lagoons from 2427 May 1992 was a "fallout" phenomenon linked to inclement weather and coincided with exceptional concentrations of up to 45 Eastern Kingbirds and 180 Black Terns at the same location.

Finally, I note that the Common Nighthawk has probably disappeared as a breeding bird in Pinawa. Around 1980 a few nighthawks were regularly heard over the town on summer evenings. They were thought to be nesting on flat-roofed buildings. ${ }^{7}$ There have been no such observations in recent years.

Acknowledgements I thank Rudolf F. Koes for information and helpful comments.

1. ARBIB, R.S. 1976. The Blue List for 1976. Am. Birds 29:1067-1072.

2. CAMPBURN, K.E. 1986. Common Nighthawk migration along the north shore in Duluth. Loon 58:197.

3. CARLEY, J.R. 1993. More on Common Nighthawk migration. Ont. Birds 11:82.

4. DE GRAAF, K. 1978. Large concentration of Common Nighthawks. Blue Jay 36:122.

5. EWINS, P.J. 1993. Common Nighthawks foraging in large flocks on migration. Ont. Birds 11:75-77.

6. HENDRICKSON, M. and K. ECKERT. 1991. A record movement of Common Nighthawks. Loon 63:68-69.

7. TAYLOR, P. 1983. Wings along the Winnipeg: the birds of the Pinawa Lac du Bonnet region, Manitoba. Eco Series No. 2, Manitoba Naturalists Society, Winnipeg. 216 pp.

8. TAYLOR, P. 1993. Migration of Bonaparte's Gull, Larus philadelphia, in southeastern Manitoba. Can. FieldNat. 107:314-318.

9. WEDGWOOD, J. 1992. Common Nighthawks in Saskatoon. Blue Jay 50:211-217. 